\title{
Leaching Behavior and Risk Control of Waste Mercury Chloride Catalyst Through Mechanochemical Reaction Using Sulfur
}

\author{
Yafeng Ren and Jianxin Zhu* \\ Research Center for Eco-Environmental Sciences, Chinese Academy of Sciences, Beijing, China.
}

Received: January 8, 2015 Accepted in revised form: June 17, 2015

\begin{abstract}
A large volume of waste mercury chloride catalyst $\left(\mathrm{HgCl}_{2}\right)$ is generated by calcium carbide-based polyvinyl chloride production in China, which accounts for $30 \%$ of global mercury consumption. However, there are few studies on the leaching behavior and risk control of waste catalyst where mercury is in the form of $\mathrm{HgCl}_{2}$, which is more soluble than metal mercury and poses great threat to human health and environment. This study investigated mechanochemical stabilization and leaching behavior of waste mercury catalyst using sulfur as additive. We found that mercuric sulfide $(\mathrm{HgS})$ formed through mechanical milling, although the reaction between $\mathrm{HgCl}_{2}$ and $\mathrm{S}$ is not thermodynamically favored. Moreover, toxicity characteristic leaching procedure (TCLP) results showed mercury leaching values are lower than the TCLP limit value of $0.2 \mathrm{mg} / \mathrm{L}$ after mechanochemical treatment. Results of sequential extraction procedure showed that ball mill could transfer more than $99.9 \%$ of the $\mathrm{Hg}$ in the catalyst to the least mobile fraction.
\end{abstract}

Key words: leaching behavior; mechanochemistry; mercury chloride catalyst; risk control; sulfur

\section{Introduction}

$\mathbf{I}$

N CHINA, MERCURY CHLORIDE CATALYST is massively used in the production of polyvinyl chloride (PVC) via the calcium carbide process, accounting for $80 \%$ of the total output of PVC in China (China Chloro-Alkali Industry Association, 2011). The catalyst, which is activated carbon impregnated with $7-12 \% \mathrm{HgCl}_{2}$, ensure the selectivity and reactivity of vinyl chloride monomer formation (Ren et al., 2014). Since China is the world's largest producer of PVC, this industry consumes 12,000 tons of $\mathrm{HgCl}_{2}$-catalyst each year, which accounts for $60 \%$ of the mercury consumption in China and $30 \%$ of the global mercury consumption and has become the largest consumer of mercury in the world (Zhou, 2011). About 13,000 tons of waste mercury chloride catalyst, which normally contains $4-7 \% \mathrm{HgCl}_{2}$, were generated annually (Zhang and $\mathrm{Wu}, 2008)$. The generating volume will grow at the rate of $10-15 \%$ over the next years (Zhang and $\mathrm{Li}$, 2014). Therefore, the large volume of waste mercury catalyst will pose potential risk to eco-environment and human health and place heavy pressure on China to reduce mercury use and prevent mercury release to the environment.

According to the research, inorganic mercury can pose a threat to the gastrointestinal tract, immune system, and the kidneys (Clarkson, 1993; Holmes et al., 2009). Organomercury is more toxic and more easily bioaccumulated than in-

*Corresponding author: Research Center for Eco-Environmental Sciences, Chinese Academy of Sciences, No. 18 Shuangqing Road, Haidian District, Beijing 100085, China. Phone: 86-10-62849488; Fax: 86-10-62849515; E-mail: zhujx@ rcees.ac.cn organic mercury (Lacerda and Fitzgerald, 2001). Especially the methylmercury can impair the neurological development of fetuses and young children and damage the cardiovascular and central nervous system of adults (Stern, 2005; Hogberg et al., 2010). Moreover, mercury has bad effects on ecosystem processes such as microbially mediated processes and the diversity of microbial community (Ranjard et al., 1997; Gudbrandsen et al., 2007).

Considering the detrimental effects of mercury on human health and the environment, international community enact legislations and initiate world-wide efforts to reduce the supply and demand of mercury. In 2005, the UNEP launched a Global Mercury Partnership aiming to achieve reductions in mercury use and emissions globally (United Nations Environment Programme, 2013). In 2008, the United States signed the Mercury Export Ban Act, including both mercury exports and long-term mercury management and storage. European Directive listed mercury as a priority hazardous substance due to its pernicious influence (European Directive, 2000/60/EC). The EU council and European Parliament sets 2011 as the deadline to ban the industrial use of $\mathrm{Hg}$ and the mercury exports and address the issue of safe storage of metallic mercury (EU Council and European Parliament Regulation, 1102/2008). In 2013, the UNEP enacted Minamata Convention on Mercury aimed to control mercury pollution and reduce mercury releases (Minamata Convention on Mercury, 2013). And China was among the first countries to sign the convention. As the largest calcium carbide-based PVC producing country, Chinese government will restrict the use of high-mercury catalyst in 2015 and phase out the mercury chloride catalyst (Wang, 2013). 
In China's PVC production industry, the $\mathrm{HgCl}_{2}$ in the waste mercury catalyst could be recycled and used as raw material for reproduction of mercury catalyst. Both of the pyrometallurgical process and hydrometallurgy process are commonly adopted for the recycling of $\mathrm{HgCl}_{2}$ (Zhang, et al., 2008). However, it is found that less than $1 / 3$ the waste mercury catalyst was recovered, and the recovery ratio is only $90 \%$ and about $10 \%$ of the mercury was released into the environment (Zhang, 2014). Large amount of the waste catalyst was just dumped into the surround environmental without further treatment and since the soluble and volatile property of $\mathrm{HgCl}_{2}$, the $\mathrm{HgCl}_{2}$ is easily leached from waste catalyst into environment. The safe disposal of waste mercury catalyst is urgent for the environmental sound management and risk control of mercury waste in China.

Most of the research on the treatment of mercury waste focus on the disposal of metal mercury-containing waste. The primary treatments include amalgamation, stabilization/ solidification, vitrification, thermal desorption, chemically bonded phosphate ceramics nanotechnology, soil washing, formation of sulfides of mercury, phytostabilization, phytoextration and other treatment technologies (Randall and Chattopadhyay, 2004; Wang et al., 2012). These methods require high temperature process or long operation time; the release of mercury may be a secondary pollution. Due to the advantages such as solvent-free and nonheating, mechanochemical method is widely used in waste treatment, such as the disposal of persistent organic pollutants (Lu et al., 2012). But few studies about mechanochemical method are reported to be applied in the treatment of mercury-containing wastes. Lopez et al. (2010) and Fukuda et al. (2014) used planetary ball mill to stabilize mercury by milling with sulfur and mercuric sulfide was formed. Ball milling is potentially a promising way for the treatment of mercury catalyst because of its low temperature, solvent-free and safe operation condition. And according to our knowledge, there is no report about the treatment of waste mercuric chloride by mechanochemical method up to now.

The aim of this research is to study the feasibility to stabilize mercuric chloride catalyst by using the mechanical energy provided by ball milling at room temperature. The objective is to find a simple and cost-effective manner to transform the mercury in waste mercuric chloride catalyst into a stable mercury compound for long-term disposal. Toxicity characteristic leaching procedure (TCLP) was carried out to evaluate the leachability of mercury for all the samples. Moreover, to gain a better understanding of the stabilization process, the binging forms of $\mathrm{Hg}$ in milling samples were analyzed by five-step sequential extraction procedure (SEP) based on the work of Jeyakumar et al. (2008) for the determination of specific fractionation of $\mathrm{Hg}$ in soil (Wang et al., 2011).

\section{Materials and Methods}

\section{Materials and mercury chloride catalyst preparation}

Mercury(II) chloride (AR, 99.5\%) was purchased from Shenyang Chemical Plant. Mercury standard solution was obtained from CRM/RM information center of China. Activated carbon, sublimed sulfur (S, AR, 99.5\%), sodium hydroxide $(\mathrm{NaOH}, \mathrm{AR}, 99.6 \%)$, and sodium acetate anhydrous $(\mathrm{NaOAc}$, AR, 99\%) were bought from Sinopharm Chemical Reagent Co.
Ltd. Hydroxylammonium chloride $\left(\mathrm{NH}_{2} \mathrm{OH} \cdot \mathrm{HCl}, \mathrm{GR}, 99 \%\right)$ was purchased from Aladdin.

The method for preparing catalyst used in this study was carried out according to the following steps: (1) The preparation of $\mathrm{HgCl}_{2}$ solution: $8.2 \mathrm{~g} \mathrm{HgCl}_{2}$ was added to $100 \mathrm{~g}$ ultrapure water and dissolved; (2) Impregnation: $74 \mathrm{~g}$ activated carbon was added to the solution and was kept in stirring for $6 \mathrm{~h}$; (3) Filtration: The solid and liquid phase were separated through a filter paper; (4) Drying: The impregnated activated carbon was kept at $120^{\circ} \mathrm{C}$ for $24 \mathrm{~h}$ in electric blast drying oven. The content of mercury chloride in the prepared catalyst was $5.7 \%$.

\section{Ball milling}

Reaction between sulfur and mercury chloride catalyst was catalyzed by the mechanical energy provided by a planetary ball mill (QM-3SP2J; Nanjing University Instrument Corporation). Mixtures of catalyst and sulfur at the mass ratio of 1:1, 1:2, 1:4, $1: 8,1: 20$, and $1: 40$ were ground for $12 \mathrm{~h}$. And at the mass ratio of $1: 8$, different milling time ranging between $15 \mathrm{~min}$ and $2 \mathrm{~h}$ were studied. A $250 \mathrm{~mL}$ stainless steel grinding pot was used and the ratio of ball mass to reactant mass was 40 . The rotation speed was $550 \mathrm{rpm}$ in all cases. After milling, all samples were collected and conserved in closed dryers for further use.

\section{Toxicity characteristic leaching procedure}

The milling samples were subjected to TCLP to evaluate the leachability of mercury of grinding sample (TCLP test, EPA Test Method 1311, 1922). First, a pH evaluation was made to determine the suitable extract fluid. Since the $\mathrm{pH}$ of the samples was $<5$, the TCLP extraction fluid was an acetic acid and acetate buffer solution (fluid 1).

Second, the TCLP test was conducted using $1 \mathrm{~g}$ of sample instead of the prescribed $100 \mathrm{~g}$. The amount of extraction fluid (1) used to extract the samples was equal to 20 times the weight of the solid. The samples were stirred for $18 \mathrm{~h}$ and filtered by a $45 \mu \mathrm{m}$ microfilter. The filtrates were acidified by nitric acid to $\mathrm{pH}<2$ and stored at $4^{\circ} \mathrm{C}$. The performance of the $\mathrm{Hg}$ analysis was carried out using inductively coupled plasma optical emission spectrometry (ICP-OES). The samples, of which concentration is lower than the detection limit of ICP-OES, were analyzed by mercury vapourmeter (Milestone; DMA-80).

\section{Sequential extraction procedure}

SEP allowing the determination of five fractions of mercury was performed. One gram of milling sample was treated by the following steps:

(i) Soluble and exchangeable. The milling samples were extracted at room temperature, kept in stirring for $1 \mathrm{~h}$ with $8 \mathrm{~mL}$ of magnesium nitrate $\left[1 \mathrm{M} \mathrm{Mg}\left(\mathrm{NO}_{3}\right)_{2}\right]$, and separated by a $0.45 \mu \mathrm{m}$ filter.

(ii) Specifically sorbed. The residue (i) was treated at room temperature with $8 \mathrm{~mL}$ extractant $(1 \mathrm{M} \mathrm{NaOAc}$, adjusted to $\mathrm{pH}=5.0$ with acetic acid) and kept in stirring $5 \mathrm{~h}$, then filtrated.

(iii) Oxide-bound. The residue from (ii) was extracted with $20 \mathrm{~mL}$ of $0.4 \mathrm{M} \mathrm{NH} \mathrm{NH}_{2} \mathrm{OH} \cdot \mathrm{HCl}$ (dissolved in $25 \%$ $\mathrm{HOAc}$ ). The latter experiment was performed $6 \mathrm{~h}$ at $96^{\circ} \mathrm{C}$ in a water bath, and then filtrated. 
(iv) Organic-bound. For the residue from (iii), $8 \mathrm{~mL}$ of $30 \%$ $\mathrm{H}_{2} \mathrm{O}_{2}$ (adjusted to $\mathrm{pH}=2$ with $\mathrm{HNO}_{3}$ ) was added and the mixture was heated $2 \mathrm{~h}$ at $85^{\circ} \mathrm{C}$ in a water bath. After $2 \mathrm{~h}$, a second $3 \mathrm{~mL}$ of $\mathrm{H}_{2} \mathrm{O}_{2}(\mathrm{pH}=2.0)$ was added and the sample was heated $3 \mathrm{~h}$ at $85^{\circ} \mathrm{C}$ in water bath.

(v) Residual. The residue remaining from (iv) was digested with $5 \mathrm{~mL}$ of aqua regia and heated $1 \mathrm{~h}$ at $95^{\circ} \mathrm{C}$ in a water bath.

By comparing the mercury concentration of milling samples determined by single digestion with the sum of the five individual fractions, the ability of this SEP to account for all sample mercury was evaluated.

\section{Chemical and physical analyses}

Determination of total mercury. For the total mercury analysis, the samples before and after ball milling were digested with concentrated $\mathrm{HNO}_{3}$. And the mercury concentration in digestion liquid was determined by ICP-OES.

Scanning electron microscope and X-ray diffraction analysis. To illustrate the immobilization mechanisms and to verify whether alteration occurred during milling, scanning electron microscope (SEM) microanalysis was performed to analyze the $\mathrm{HgCl}_{2}$ distribution on activated carbon and X-ray diffraction (XRD) analyses were also performed to determine the crystalline phases of grinding samples. Moreover, XRD analyses were conducted by XRD (RINT; Rigaku) using $\mathrm{Cu}$ $\mathrm{K} \alpha$ Ni-filtered radiation $(\lambda=15.418 \AA)$. XRD data were collected at values of $2 \theta$ of $10-90^{\circ}$.

\section{Results and Discussion}

\section{TCLP results}

Results of TCLP tests for samples obtained as a function of the mass ratio of catalyst to sulfur. In this section, the effect of mass ratio on the stabilization of waste catalyst was studied. The mixtures of mercury catalyst and sulfur, at the mass ratio of catalyst to sulfur for 1:1, 1:2, 1:4, 1:8, 1:20, and 1:40, were milled for $12 \mathrm{~h}$ and then subjected to TCLP test. The TCLP results of the milling samples are shown in Fig. 1.

First, the catalyst used in the milling process was carried through TCLP test for comparison purposes, and the leaching result was $116.25 \mathrm{mg} / \mathrm{L}$ much higher than the EPA permissible maximum value for normal wastes. For the milling samples, the results of TCLP test showed that the mercury leaching content decreased as the charge ratio of catalyst and sulfur increased up to $1: 40$. When the mass ratio increased from $1: 1$ to $1: 2$, the leaching concentration of $\mathrm{Hg}$ was rapidly reduced from 3.47 to $0.21 \mathrm{mg} / \mathrm{L}$.

At the mass ratio of $1: 8$, the TCLP value was $0.08 \mathrm{mg} / \mathrm{L}$ and at the larger mass ratio the value was lower. Zhang and Bishop (2002) used activated carbon and cement to fulfill the stabilization and solidification of mercury-containing waste. The TCLP leaching concentration was lower than $0.01 \mathrm{mg} / \mathrm{L}$, which is at the same order of magnitude as in this study. The mercury leaching concentration was lower than the US-EPA Maximum Concentration of Contaminants for the Toxicity Characteristic $0.2 \mathrm{mg} / \mathrm{L}$. According to the Chinese Identification standards for hazardous wastes and Identification for extraction toxicity (GB 5085.3-2007), the mercury leaching concentration was also lower than the standard value of

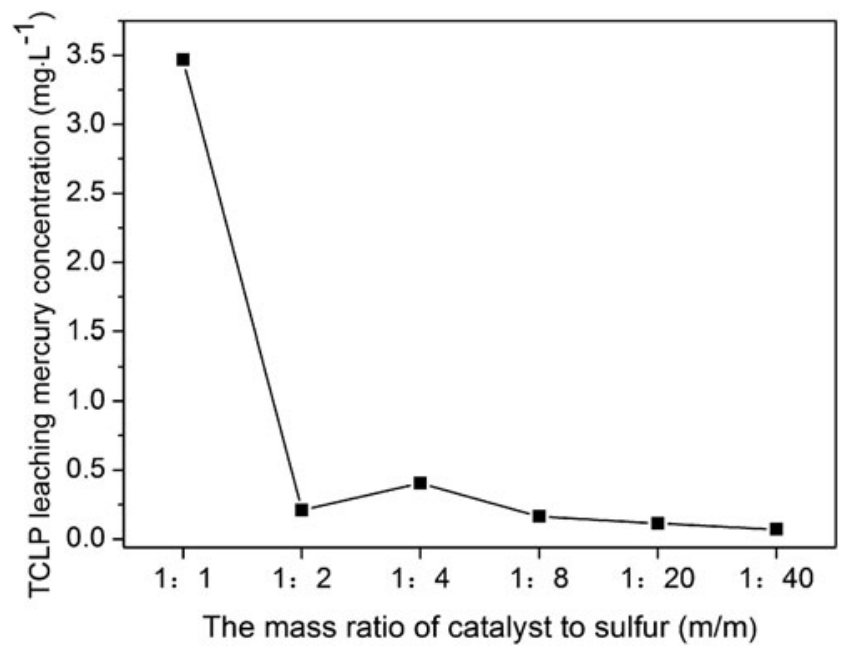

FIG. 1. Toxicity characteristic leaching procedure (TCLP) leaching concentration of mercury of samples obtained by milling the mixtures of mercury catalyst and sulfur for $12 \mathrm{~h}$ at the mass ratio of mercury catalyst to sulfur for 1:1, 1:2, $1: 4,1: 8,1: 20$, and 1:40.

$0.1 \mathrm{mg} / \mathrm{L}$. The waste catalyst after ball milling with sulfur can be characterized as normal waste according to the hazardous waste characteristics regulations. Sulfur is potentially an effective reagent for the stabilization of mercury in waste mercury catalyst by ball milling.

Results of TCLP tests for samples as a function of time. To explore the effect of milling time on the stabilization of waste $\mathrm{Hg}$-catalyst, the mixture of catalyst and sulfur at the mass ratio of 1:8 was ground for $15,30,45,60,75,90,105$, 120 , and $240 \mathrm{~min}$. All the samples at each milling time were collected and TCLP tests were implemented to evaluate the mercury leachability.

The results were given in Fig. 2. It was found that as the milling time increased the TCLP leaching values of grinding

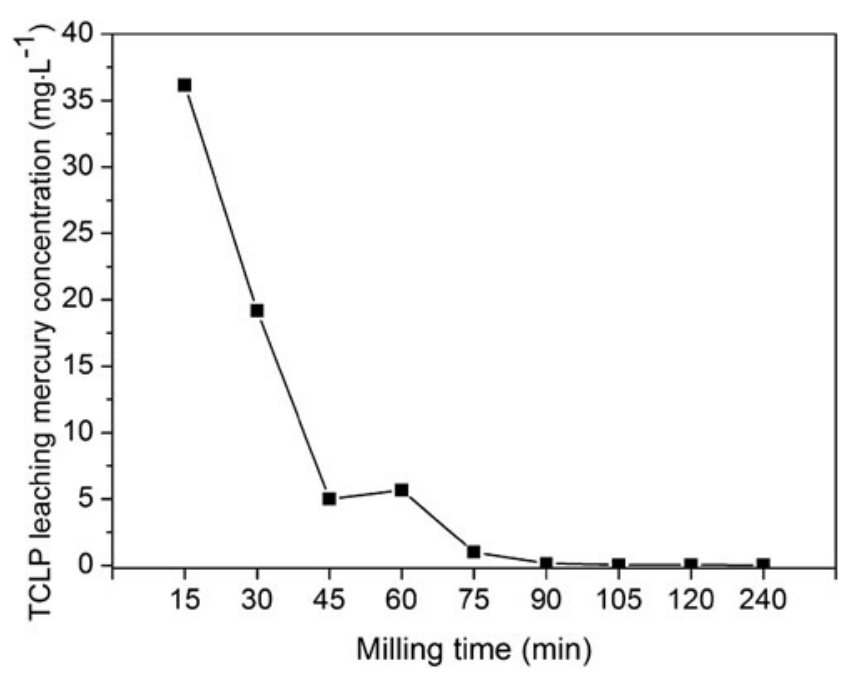

FIG. 2. TCLP leaching concentration of mercury of samples obtained by milling the mixtures of mercury catalyst and sulfur for $15,30,45,60,75,90,105,120$, and $240 \mathrm{~min}$ at the mass ratio for $1: 8$. 


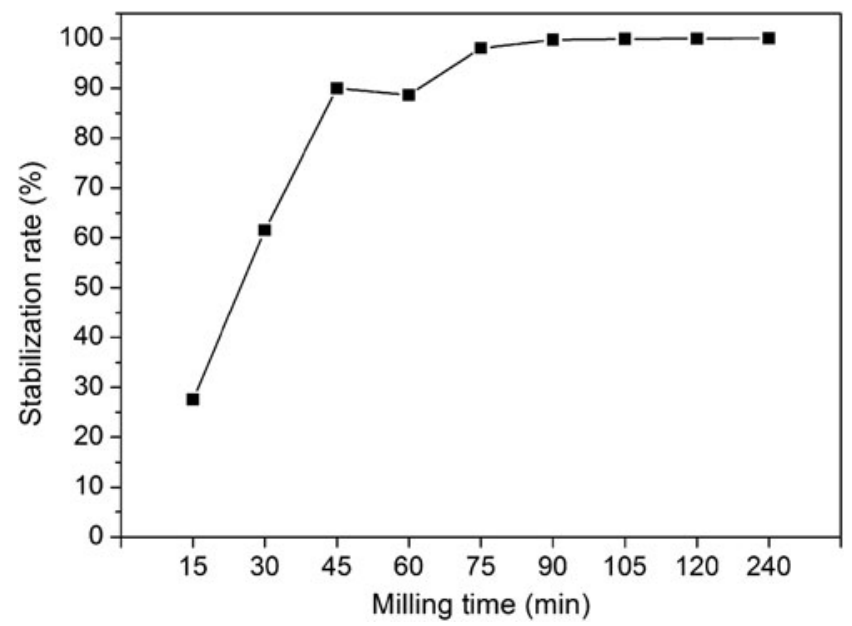

FIG. 3. Stabilization rates based on TCLP results of milling samples obtained by milling the mixtures of mercury catalyst and sulfur for $15,30,45,60,75,90,105,120$, and $240 \mathrm{~min}$ at the mercury catalyst to sulfur mass ratio of 1:8.

sample decreased. In the first $45 \mathrm{~min}$, the leaching values rapidly declined from 49.89 to $5.01 \mathrm{mg} / \mathrm{L}$. As the milling time increased up to $90 \mathrm{~min}$, the leaching value of $0.14 \mathrm{mg} / \mathrm{L}$ can pass the TCLP limit value of $0.2 \mathrm{mg} / \mathrm{L}$. With increasing milling time, the leaching value was $0.01 \mathrm{mg} / \mathrm{L}$ at $120 \mathrm{~min}$. Fuhrmann et al. (2002) treated mercury wastes by using powdered polymer cement and sulfide and the mercury in the leachate of TCLP test was $0.025 \mathrm{mg} / \mathrm{L}$, which is close to the TCLP result in this study. The result showed that as the milling time increased, co-milling with sulfur can effectively reduce the leachability of mercury.

Based on the TCLP results, the milling stabilization rates were calculated as per the following equation to further assess the $\mathrm{Hg}$ stabilization effectiveness (Zhang et al., 2009). The formula was shown as the following:

$$
S_{R}=\frac{V_{u}-V_{t}}{V_{u}} \times 100 \%
$$

where $S_{R}$ is the stabilization efficiency of $\mathrm{Hg}(\mathrm{II})$ in mercury catalyst; $V_{u}$ is the TCLP Hg leaching value for untreated sample; $V_{t}$ is the TCLP Hg leaching quantity for treated $\mathrm{Hg}$ catalyst after ball milling. And the results were presented in Fig. 3.

Results showed that the stabilization efficiencies of milling samples rapidly increased from $27.5 \%$ at $15 \mathrm{~min}$ to $90 \%$ at $45 \mathrm{~min}$, and the stabilization efficiencies of samples after milling were increased to $99.9 \%$ as the milling time increased up to $120 \mathrm{~min}$. Zhang et al. (2009) utilized thiol-functionalized zeolite and cement to stabilize and solidify the mercurycontaining solid wastes. The stabilization efficiencies can reach more than $99 \%$ for all of the cement dosages. Piao and Bishop (2006) found that the stabilization efficiencies based on the TCLP results were higher than $99 \%$ too.

\section{SEP results}

The total mercury concentrations can provide information about the degree of mercury pollution, but little knowledge on the potential eco-environmental risk and potential mobility of $\mathrm{Hg}$. The different mercury species or the fractionation of mercury provides useful information on toxicology, bioavailability, and biogeochemical reactivity (Issaro et al., 2009). By utilizing different chemical reagents, the SEP are frequently used to determine the mental fractions in soil, sediment, and other solid contaminants (Fernandez-Martinez and Rucandio, 2014; Fernandez-Martinez et al., 2014).

Change of mercury fractions as a function of time. The binding forms of mercury in the grinding samples, determining the mobility of bioavailable $\mathrm{Hg}$, were analyzed by SEP (Kaplan et al., 2000). The results of each fraction of mercury analyzed in the milling samples are presented in Supplementary Table S1. The mercury distribution in each fraction was displayed in Fig. 4. And the $\mathrm{Hg}$ recovery rare was also assessed by comparing the sum of $\mathrm{Hg}$ concentration in each fraction with the measured total $\mathrm{Hg}$ concentration. The total mercury recovery rate ranged between $102 \%$ and $118 \%$, shown in Supplementary Table S2. Wang et al. (2011) reported that the recovery rate of total mercury was in the range of $84 \%$ to $116 \%$.

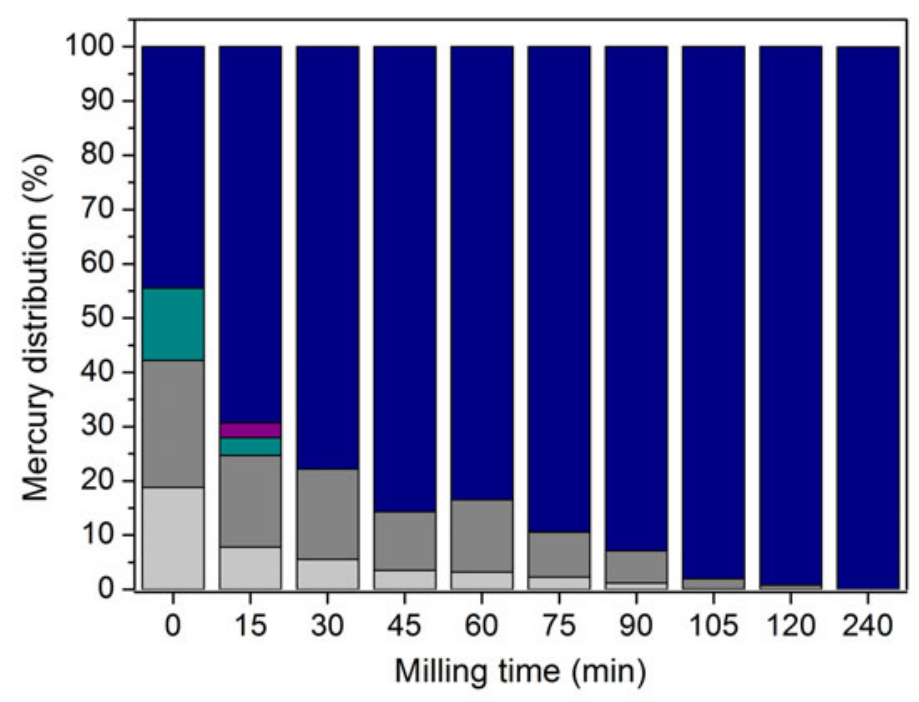

FIG. 4. Percentages of mercury distributed in the variously extracted fractions for the samples obtained by milling the mixtures of mercury catalyst and sulfur for $15,30,45,60,75,90,105,120$, and $240 \mathrm{~min}$ at the mercury catalyst to sulfur mass ratio of 1:8. 
Mercury in the soluble and exchangeable fraction $(\mathrm{F} 1)$ and the specifically sorbed fraction (F2) rapidly decreased with the increase of the milling time. Mercury in F1 is bound to the surface of milling samples and may be easily transported under natural process (Renneberg and Dudas, 2001). Mercury in F2 was possibly in a loosely binding form on the surface of the micropore of activated carbon. Mercury in these two fractions can be easily released into environment under acidic conditions (Zagury et al., 2006). After $240 \mathrm{~min}$ milling, the mercury associated with the soluble and exchangeable fraction and the specifically sorbed fraction was not observed. This change demonstrated that ball milling process may chance the transformation of mercury fractions in mercury catalyst.

For all the samples, the mercury in the oxide-bound fraction (F3) and the organic fraction (F4) were lower than $1.0 \mathrm{mg} / \mathrm{kg}$ except the $15 \mathrm{~min}$ sample. Compared with the total mercury, the mercury in these two fractions was almost negligible. The residual fraction (F5) of the milling samples was the mercury bound to sulfide, which is normally unavailable for methylation due to its very low solubility $\left(10^{-54}\right.$ mol/L) (Rytuba, 2003). It was reported that the mercury mainly existed as $\mathrm{HgS}$ in sediment and soil, one of the major sinks of Hg (Ramasamy et al., 2012). This binging form of $\mathrm{Hg}$ is important to environment risk because the very low solubility restrain the mobilization of mercury. In contrast, the $\mathrm{Hg}$ in the first four fractions was unstable and will easily enter the environment, causing local atmospheric pollution.

Change of mercury fractions as a function of the mass ratio of catalyst to sulfur. The specific sequential extraction was also carried out to determine the mercury speciation and evaluate mercury mobility, availability, and bioaccumulation in the milling samples for different mass ration of catalyst to sulfur. The percentage of mercury in each fraction of milling samples were shown in Supplementary Table S3. The total mercury recovery rate was between $92.7 \%$ and $125.3 \%$, shown in Supplementary Table S4. This was close to the mercury recovery rate of Wang's research, which ranged between $84 \%$ and $116 \%$ (Wang et al., 2011).

After $12 \mathrm{~h}$ ball milling, the mercury in F1, F2, F3, and F4 were nearly zero for all the grinding samples. And the largest $\mathrm{Hg}$ portion of all the milling samples was the residual fraction, which was not available for methylation. The residual fraction accounted for $99 \%$ of the sum of each fraction, even nearly $100 \%$ for $1: 8,1: 20$, and $1: 40$. During the milling process, the mercury in catalyst was transformed from the first four fractions to the residual fraction. And the mercury in residual fraction was greatly influenced by the sulfur content in the milling process: the larger sulfur content, the higher conversion rate of the residual fraction. According to Li's research (Li et al., 2010), the mercury in this fraction is the least bioavailable form of $\mathrm{Hg}$ under natural environmental conditions because of the low solubility of sulfur-bound mercury.

Relationship between TCLP and SEP. Mercury leaching concentration of TCLP test was greatly affected by mercury speciation in the milling samples. The correlativity between the mercury distribution derived from SEP and the leaching content of Hg in TCLP test was analyzed. The relationship between TCLP and SEP was correlated by calculating the ratio of TCLP leaching values to $\mathrm{F} 1$; the sum of $\mathrm{F} 1$ and $\mathrm{F} 2$; the sum of F1, F2, and F3; the sum of F1, F2, F3, and F4; and the sum of the five fractions. The results, presented in Fig. 5, showed that the ratio declined between TCLP leaching value to F1 and the sum of F1 and F2. And there was no significant difference among the ratio of TCLP leaching value to the sum of F1 and F2; the sum of F1, F2, and F3; and the sum of F1, $\mathrm{F} 2, \mathrm{~F} 3$, and F4.

Comparing with Fig. 2, we found that in Fig. 5 as the mercury content in the first two fractions decreased, the leaching concentration of mercury in TCLP test declined too. The source of mercury in TCLP test was possibly the mercury in the soluble and exchangeable and the specifically sorbed fractions (Xie and Zhu, 2013). It was reported that heavy metals in the exchangeable and soluble and the specifically sorbed fraction were easily liberated into the environment under acid condition. As mercury in the residual fraction was the least mobile and relatively stable, we concluded that the mercury in TCLP leaching fraction were mainly resulting from the mercury in the exchangeable and soluble and the specifically sorbed fractions.

\section{Mercury loss during the milling process}

Mercury concentration before and after ball milling experiment and the loss ratio of mercury were analyzed and presented in Supplementary Tables S5 and S6. The loss ratio of mercury was between $0.1 \%$ and $4.5 \%$ for the samples obtained at different mass ratio. When the mass ratio increased, the loss ratio of mercury decreased, ranging from $0.09 \%$ to $3.2 \%$. Excessive sulfur might prevent the loss of mercury during the milling process. And the research of

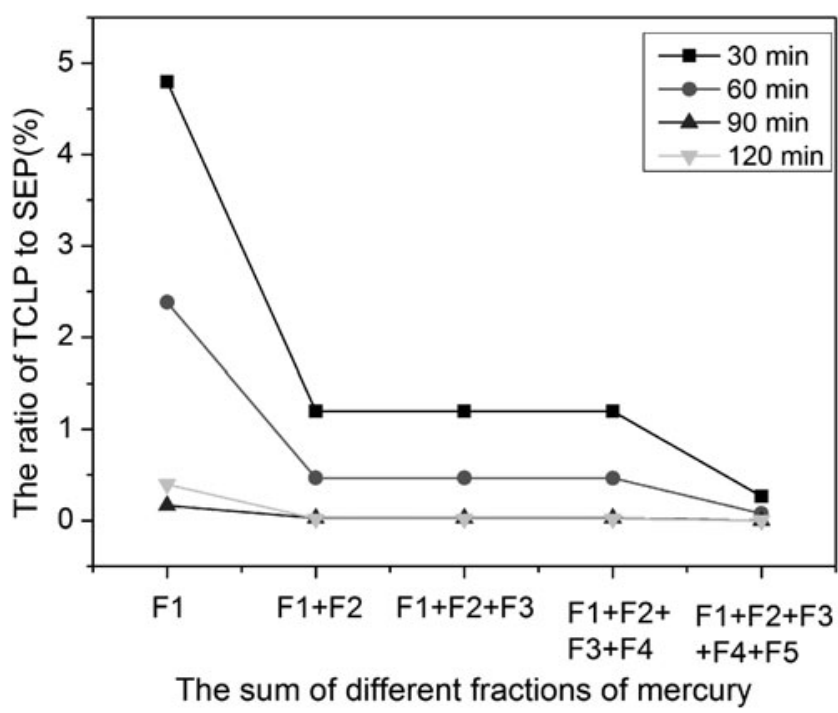

FIG. 5. Correlativity between the mercury distribution derived from sequential extraction procedures (SEP) and the leaching content of $\mathrm{Hg}$ in TCLP test. The relationship between TCLP and SEP was correlated by calculating the ratio of TCLP leaching values to F1; the sum of F1 and F2; the sum of F1, F2, and F3; the sum of F1, F2, F3, and F4; and the sum of the five fractions. (F1, the soluble and exchangeable fraction; F2, the specifically sorbed fraction; F3, the oxide-bound fraction; F4, the organic-bound fraction; $\mathrm{F} 5$, the residual fraction. 
Fukuda also indicated that excess sulfur inhibited the vaporization of mercury in the process of ball mill (Fukuda et al., 2014).

For the sample milled at the mass ratio of $1: 8$ for different time, the loss of mercury was in the range of $0.9-2.7 \%$. This demonstrated that the milling process was able to stabilize the mercury in mercury chloride catalyst. The loss of mercury might be due to the volatile property of mercuric chloride and the warming effect of ball milling. And better seal measures would be recommended to prevent the loss of mercury during the milling process possibly causing secondary pollution.

\section{Micrograph of samples}

Morphology of the prepared catalyst and the milling sample of 1:8 were characterized by SEM and are shown in Fig. 6. $\mathrm{HgCl}_{2}$ aggregate on the surface of activated carbon in drusy state. The druse site was affected by the microstructure of activated carbon, and the coarse surface favored the formation of druse. After ball milling, the microstructure was destroyed and the surface of activated carbon was covered
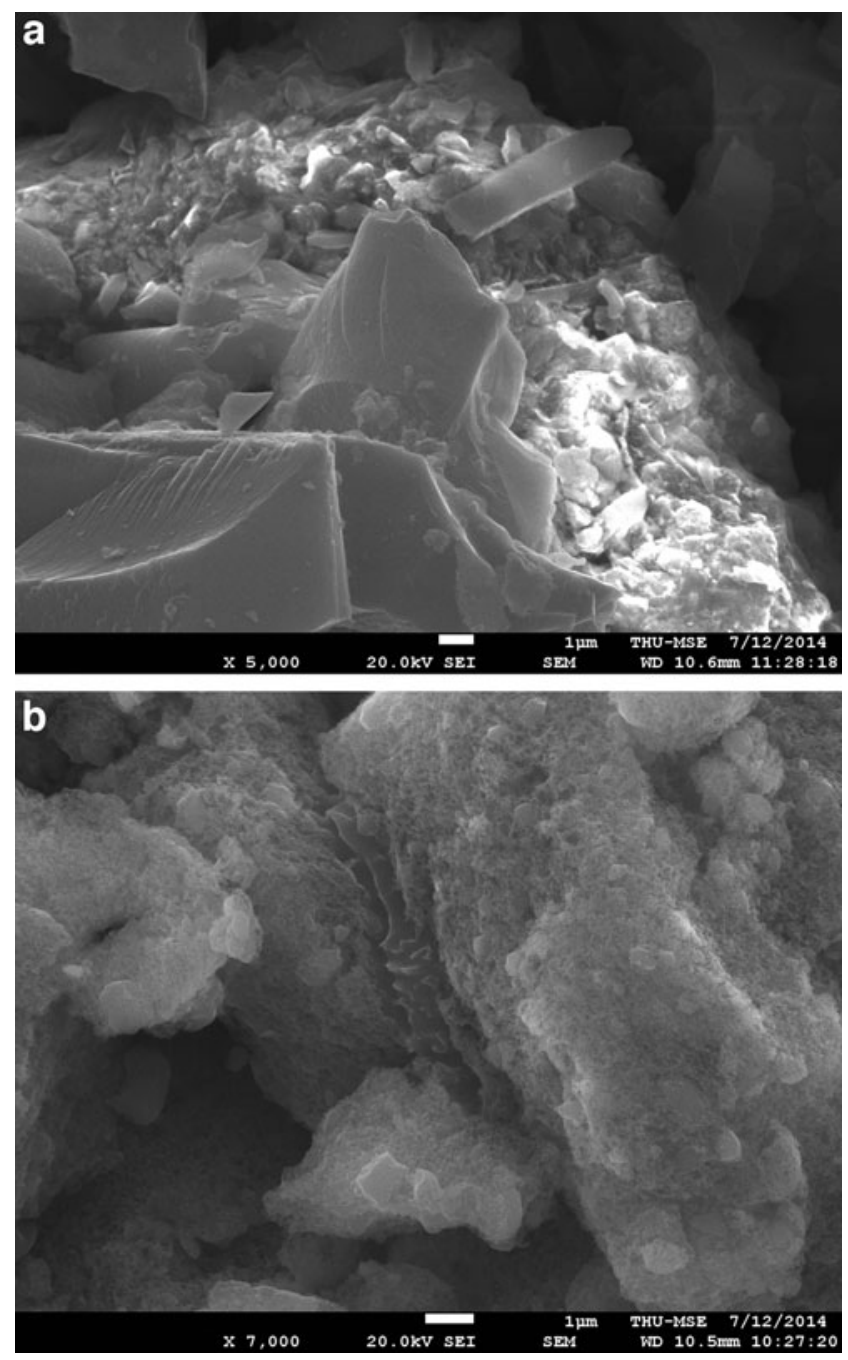

FIG. 6. Scanning electron microscope images of: (a) nontreated mercury catalyst; (b) the sample obtained by milling the mixture of mercury catalyst and sulfur for $12 \mathrm{~h}$ at the mercury catalyst to sulfur mass ratio of 1:8.

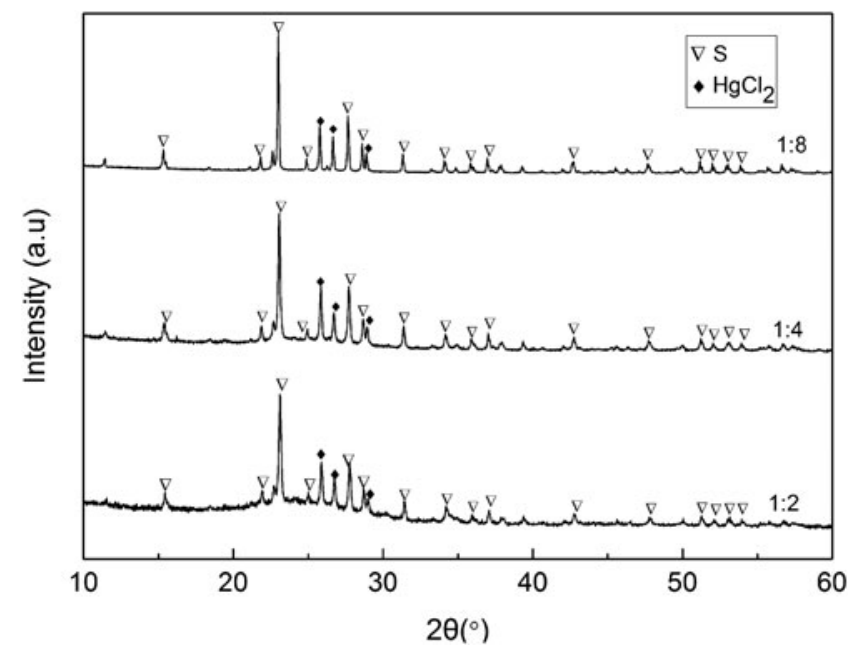

FIG. 7. X-ray diffraction patterns of samples obtained by milling of mercury catalyst and sulfur for $12 \mathrm{~h}$ at mercury catalyst to sulfur mass ratio of $1: 2,1: 4$, and 1:8.

with sulfur adequately. Due to the existence of a mass of sulfur, mercury compounds in catalyst dispersed in the mixture.

\section{Preliminary study of stabilization mechanism}

The XRD results shown in Fig. 7 demonstrated that after ball milling crystalline mercury sulfide $(\mathrm{HgS})$ was detected in the milling samples. In other words, $\mathrm{HgS}$ was formed by the co-milling of catalyst and sulfur. We all know that the formation of mercuric sulfide from the reaction between sulfur and mercury ( $\mathrm{Hg}+\mathrm{S} \rightarrow \mathrm{HgS}$ ) is favored thermodynamically. Lopez et al. (2010) used planetary ball milling to study the formation of metacinnabar from the mixture of liquid mercury and sulfur. There was no mercury after $120 \mathrm{~min}$ of milling and the milling process accelerated the formation of $\mathrm{HgS}$. And Svensson (Svensson et al., 2006) found that sulfur would react with mercury oxide $(\mathrm{HgO})$ to form mercuric

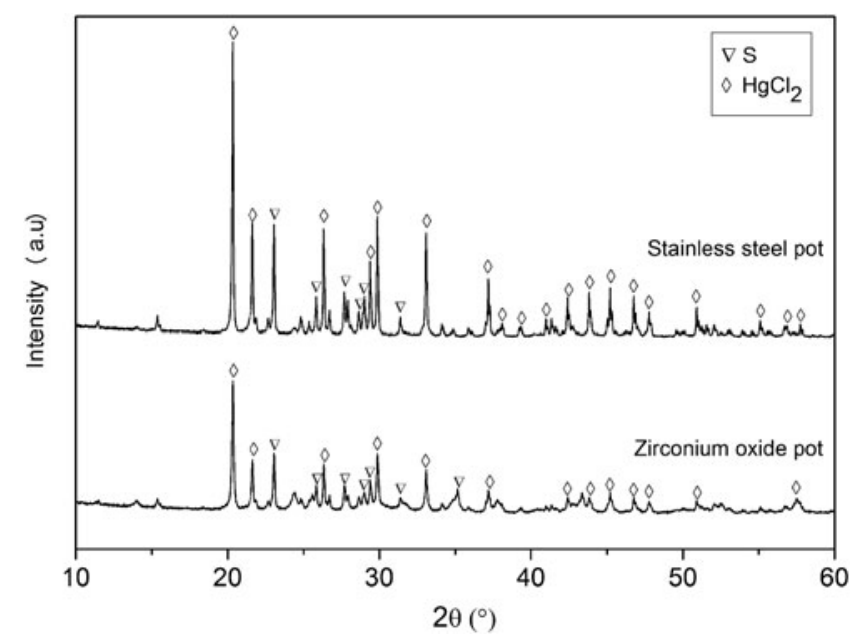

FIG. 8. X-ray diffraction patterns of samples ground in different materials of mill pot. The mixture of mercury chloride $(2 \mathrm{~g})$ and sulfur $(2 \mathrm{~g})$ was milled in stainless pot and zirconia pot respectively. 


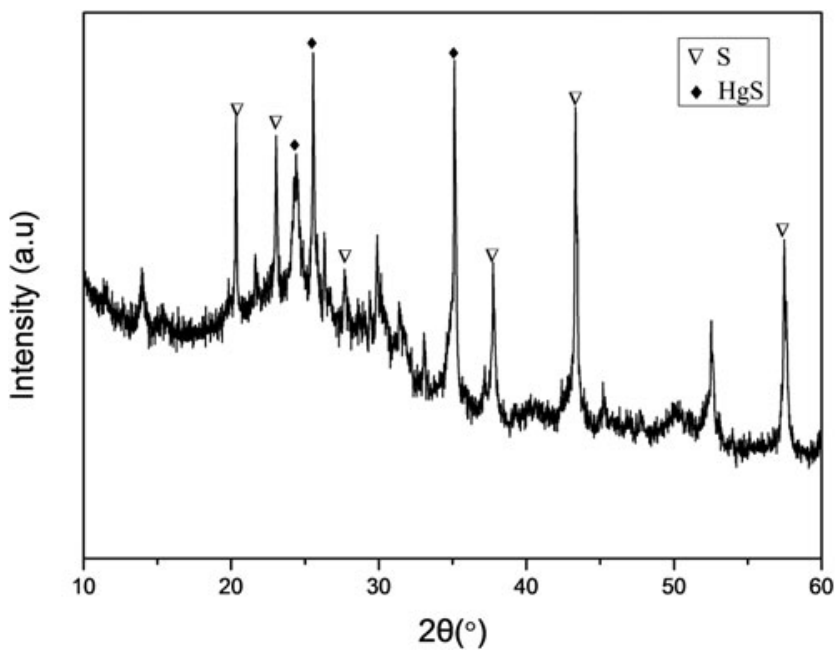

FIG. 9. X-ray diffraction patterns of samples obtained by milling the mixture of mercuric chloride $(1 \mathrm{~g})$, activated carbon $(1 \mathrm{~g})$, and sulfur $(1 \mathrm{~g})$ for $12 \mathrm{~h}$ at the mercury catalyst to sulfur mass ratio of $1: 2,1: 4$, and $1: 8$.

sulfide. But no research about the formation of $\mathrm{HgS}$ from $\mathrm{HgCl}_{2}$ and sulfur were studied.

In this study, after the milling of the mixture of mercury catalyst and sulfur, $\mathrm{HgS}$ was formed during the milling process. The $\Delta_{\mathrm{r}} \mathrm{G}_{\mathrm{m}}$ of the reaction between $\mathrm{HgCl}_{2}$ and $\mathrm{S}$ $\left(\mathrm{HgCl}_{2}+\mathrm{S} \rightarrow \mathrm{HgS}+\mathrm{Cl}_{2}\right)$ is $128 \mathrm{~kJ} / \mathrm{mol}$. From the thermodynamic view, this means that the reaction between $\mathrm{HgCl}_{2}$ and $\mathrm{S}$ was not thermodynamically favored. We supposed that iron derived from stainless steel ball and pot might serve as electron donor. The $\Delta_{\mathrm{r}} \mathrm{G}_{\mathrm{m}}$ of the reaction between $\mathrm{HgCl}_{2}, \mathrm{~S}$, and $\mathrm{Fe}$ $\left(\mathrm{HgCl}_{2}+\mathrm{Fe}+\mathrm{S} \rightarrow \mathrm{HgS}+\mathrm{FeCl}_{2}\right)$ is $-174.3 \mathrm{~kJ} / \mathrm{mol}$. This means that the reaction can take place from the perspective of thermodynamics. To understand the role of iron, $\mathrm{HgCl}_{2}$ and sulfur were co-grinded in stainless steel and zirconia mill pot respectively. And after $6 \mathrm{~h}$ milling, the XRD results (shown in Fig. 8) of these two samples showed that no $\mathrm{HgS}$ was detected. Then, $\mathrm{HgCl}_{2}, \mathrm{~S}$, and activated carbon were also co-grinded in zirconic pot for $6 \mathrm{~h}$. The result of XRD (shown in Fig. 9) test showed that $\mathrm{HgS}$ formed after milling treatment. The iron did not contribute to the formation of $\mathrm{HgS}$.

Therefore, we proposed that activated carbon in the milling system might play an important role in the formation of $\mathrm{HgS}$ during the milling process. In the process of ball milling, the collision between the balls and grinding pot at high rotation speed produced huge impact forces and released high dynamic energy (Lopez et al., 2010). And high impact energy can increase the number of chemically active defect site and induce mechanochemical solid phase reaction (Kim et al., 2009). Due to the collision between balls, the impact energy would catalyze the dissociation of $\mathrm{HgCl}_{2}$ on the surface of activated carbon producing $\mathrm{Hg}^{2+}\left(\mathrm{HgCl}_{2} \rightarrow \mathrm{Hg}^{2+}+2 \mathrm{Cl}^{-}\right)$ and activated carbon rapidly absorbed the $\mathrm{Cl}^{-}$, which further facilitate the course of mercuric chloride dissociation. At the same time, the generated energy and activated carbon would activate the surface of $\alpha$-sulfur resulting in the generation of $\mathrm{S}^{2-}\left(\mathrm{S}+2 \mathrm{e}^{-} \rightarrow \mathrm{S}^{2-}\right)$. Under milling environment, the fierce collision and adsorption of the $\mathrm{Cl}^{-}$on the activated carbon promoted the combination of $\mathrm{Hg}^{2+}$ and $\mathrm{S}^{2+}$ forming $\mathrm{HgS}$, expressed as $\mathrm{Hg}^{2+}+\mathrm{S}^{2-} \rightarrow \mathrm{HgS}$.

\section{Conclusion}

In this study, waste mercury catalyst and sulfur were ground by a planetary ball mill. The stable chemical state of mercury, $\mathrm{HgS}$, formed in the ball milling process. TCLP and SEP were carried out to study the leaching behavior of mercury in waste catalyst and evaluate the validity of this method and provide a comprehensive assessment of the environmental risk for this method. The ratio of catalyst to sulfur being 1:8 was the optimal charge ratio, and after 120 min of milling the leachable mercury concentration of TCLP leaching test were only $0.08 \mathrm{mg} / \mathrm{kg}$, which was much less than the EPA-TCLP limited value of $0.2 \mathrm{mg} / \mathrm{kg}$.

When the ratio of catalyst to sulfur is $1: 8$, the mercury associated with the soluble and exchangeable fraction and the specifically sorbed fraction were significantly decreased during the course of ball milling. Correspondingly, mercury in residual fraction accounted for nearly $100 \%$ of the total mercury after $120 \mathrm{~min}$ of milling. This indicates that in the milling process mercury in the soluble and exchangeable and the specifically sorbed fractions were transferred into the residual fraction. From the view of environmental risk, milling process can reduce the mercury in the soluble and exchangeable and the specifically sorbed fractions in catalyst, which are easily released into the environment. The results of our research indicated that mechanochemical process, in which waste catalyst and sulfur were ground by a planetary ball milling, could be a feasible technique to manage the mercury risk in waste mercury catalyst.

\section{Acknowledgment}

Support for this research by the Open Fund of Shanghai Cooperative Centre for WEEE Recycling (B50ZS120003) is gratefully acknowledged.

\section{Author Disclosure Statement}

No competing financial interests exist.

\section{References}

China Chloro-Alkali Industry Association (2011). The 12th five-year plan of chloro-alkali industry in China. China Chem. Ind. News 7 (in Chinese).

Clarkson, T.W. (1993). Mercury-major issues in environmentalhealth. Environ. Health Perspect. 100, 31.

Directive 2000/60/EC of the European Parliament and of the Council of 23 October 2000 establishing a framework for Community action in thefield of water policy. Official Journal L 327, 22/12/2000; 0001-0073.

Fernandez-Martinez, R., Loredo, J., Ordonez, A., and Rucandio, I. (2014). Mercury availability by operationally defined fractionation in granulometric distributions of soils and mine wastes from an abandoned cinnabar mine. Environ. Sci. Process Impacts 16, 1069.

Fernandez-Martinez, R., and Rucandio, I. (2014). Total mercury, organic mercury and mercury fractionation in soil profiles from the Almaden mercury mine area. Environ. Sci. Process Impacts 16, 333.

Fuhrmann, M., Melamed, D., Kalb, P.D., Adams, J.W., and Milian, L.W. (2002). Sulfur polymer solidification/stabilization of elemental mercury waste. Waste Manage. 22, 327.

Fukuda, N., Takaoka, M., Oshita, K., and Mizuno, T. (2014). Stabilizing conditions of metal mercury in mercury 
sulfurization using a planetary ball mill. J. Hazard. Mater. $276,433$.

Gudbrandsen, M., Sverdrup, L.E., Aamodt, S., and Stenersen, J. (2007). Short-term pre-exposure increases earthworm tolerance to mercury. Eur. J. Soil Biol. 43, S261.

Hogberg, H.T., Kinsner-Ovaskainen, A., Coecke, S., Hartung, T., and Bal-Price, A.K. (2010). mRNA expression is a relevant tool to identify developmental neurotoxicants using an in vitro approach. Toxicol. Sci. 113, 95.

Holmes, P., James, K.A.F., and Levy, L.S. (2009). Is low-level environmental mercury exposure of concern to human health? Sci. Total Environ. 408, 171.

Issaro, N., Abi-Ghanem, C., and Bermond, A. (2009). Fractionation studies of mercury in soils and sediments: A review of the chemical reagents used for mercury extraction. Anal. Chim. Acta 631, 1.

Jeyakumar, P., Loganathan, P., Sivakumaran, S., Anderson, C.W.N., and McLaren, R.G. (2008). Copper and zinc spiking of biosolids: Effect of incubation period on metal fractionation and speciation and microbial activity. Environ. Chem. 5, 347.

Kaplan, D.L., Myers, J., Knox, A.C., lverson, G., and Serkiz, S. (2000). Mercury Speciation Modeling Using Site Specific Chemical and Redox Data from the TNXOD OU. A Westinghouse Savannah River Company Report. WSRC-TR, 58, 1.

Kim, W., Bae, I., Chae, S., and Shin, H. (2009). Mechanochemical decomposition of monazite to assist the extraction of rare earth elements. J. Alloys Compd. 486, 610.

Lacerda, L.D., and Fitzgerald, W.F. (2001). Biogeochemistry of mercury in wetlands. Wetl. Ecol. Manage. 9, 291.

Li, J., Lu, Y., Shim, H., Deng, X., Lian, J., Jia, Z., and Li, J. (2010). Use of the BCR sequential extraction procedure for the study of metal availability to plants. J. Environ. Monit. 12, 466.

Lopez, F.A., Lopez-Delgado, A., Padilla, I., Tayibi, H., and Alguacil, F.J. (2010). Formation of metacinnabar by milling of liquid mercury and elemental sulfur for long term mercury storage. Sci. Total Environ. 408, 4341.

Lu, S., Huang, J., Peng, Z., Li, X., and Yan, J. (2012). Ball milling 2,4,6-trichlorophenol with calcium oxide: Dechlorination experiment and mechanism considerations. Chem. Eng. J. $195,62$.

Minamata Convention on Mercury (2013). http://mercury convention.org/ (accessed January 1, 2015).

Piao, H., and Bishop, P.L. (2006). Stabilization of mercurycontaining wastes using sulfide. Environ. Pollut. 139, 498.

Ramasamy, E.V., Toms, A., Shylesh, C.M., Jayasooryan, K.K., and Mahesh, M. (2012). Mercury fractionation in the sediments of Vembanad wetland, west coast of India. Environ. Geochem. Health 34, 575.

Randall, P., and Chattopadhyay, S. (2004). Advances in encapsulation technologies for the management of mercurycontaminated hazardous wastes. J. Hazard. Mater. 114, 211.

Ranjard, L., Richaume, A., Jocteur-Monrozier, L., and Nazaret, S. (1997). Response of soil bacteria to $\mathrm{Hg}$ (II) in relation to soil characteristics and cell location. FEMS Microbiol. Ecol. 24, 321.

The European Parliament and the Council (2008). REGULATION (EC) No 1102/2008 on the banning of exports of metallic mercury and certain mercury compounds and mixtures and the safe storage of metallic mercury, Official Journal of the European Union 304, 75.
Ren, W., Duan, L., Zhu, Z., Du, W., An, Z., Xu, L., Zhang, C., Zhuo, Y., and Chen, C. (2014). Mercury transformation and distribution across a polyvinyl chloride (PVC) production line in China. Environ. Sci. Technol. 48, 2321.

Renneberg, A.J., and Dudas, M.J. (2001). Transformations of elemental mercury to inorganic and organic forms in mercury and hydrocarbon co-contaminated soils. Chemosphere 45, 1103.

Rytuba, J.J. (2003). Mercury from mineral deposits and potential environmental impact. Environ. Geol. 43, 326.

Stern, A.H. (2005). A review of the studies of the cardiovascular health effects of methylmercury with consideration of their suitability for risk assessment. Environ. Res. 98, 133.

Svensson, M., Allard, B., and Düker, A. (2006). Formation of $\mathrm{HgS}$ - mixing $\mathrm{HgO}$ or elemental $\mathrm{Hg}$ with $\mathrm{S}, \mathrm{FeS}$ or FeS2. Sci. Total Environ. 368, 418.

Toxicity Characteristic Leaching Procedure (TCLP). US EPA, Method 1311, July, 1992. Revision 0. U.S. Environmental Protection Agency. Washington, DC.

United Nations Environment Programme (2013). Global Mercury Assessment 2013: Sources, emissions, releases, and environmental transport. www.unep.org/PDF/PressReleases/ GlobalMercuryAssessment2013.pdf (accessed January 1, 2015).

Wang, J., Feng, X., Anderson, C.W., Qiu, G., Ping, L., and Bao, Z. (2011). Ammonium thiosulphate enhanced phytoextraction from mercury contaminated soil. J. Hazard. Mater. 186, 119.

Wang, J., Feng, X., Anderson, C.W., Xing, Y., and Shang, L. (2012). Remediation of mercury contaminated sites - a review. J. Hazard. Mater. 221, 1.

Wang, L.D. (2013). Problems existing in promoting the use of low-mercury catalyst and the solutions. Polyvinyl Chloride 41, 33 (in Chinese).

Xie, Y., and Zhu, J. (2013). Leaching toxicity and heavy metal bioavailability of medical waste incineration fly ash. J. Mater. Cycles Waste Manage. 15, 440.

Zagury, G.J., Neculita, C.-M., Bastien, C., and Deschenes, L. (2006). Mercury fractionation, bioavailability, and ecotoxicity in highly contaminated soils from chlor-alkali plants. Environ. Toxicol. Chem. 25, 1138.

Zhang, J., and Bishop, P.L. (2002). Stabilization/solidification (S/S) of mercury-containing wastes using reactivated carbon and Portland cement. J. Hazard. Mater. 92, 199.

Zhou, J.H. (2011). The status and development of mercuric chloride catalyst. Econ. Anal. China Petroleum Chem. Ind. 2, 51 (in Chinese).

Zhang, P., and Li, Q.S. (2014). Developmet challenges faced by PVC produced by calcium carbide method and suggestions. Polyvinyl Chloride 42, 5 (in Chinese).

Zhang, X.Y., Wang, Q.C., Zhang, S.Q., Sun, X.J., and Zhang, Z.S. (2009). Stabilization/solidification (S/S) of mercurycontaminated hazardous wastes using thiol-functionalized zeolite and Portland cement. J. Hazard. Mater. 168, 1575.

Zhang, Y.Q. (2014). Study on regeneration of mercuric chloride catalyst with chlorine oxidation process and comprehensive utilization of tail gas. China Nonferr. Metal.. 1, 41 (in Chinese).

Zhang, Y.Q., and Wu, B. (2008). The recovery utilization of mercuric chloride catalysts during use. Polyvinyl Chloride 2, 27 (in Chinese).

Zhang, Y.X., Deng, X.D., and Wu, B. (2008). Technological progress in the production of mercuric chloride catalyst in China and the recycle of waste mercuric chloride catalyst in China. Polyvinyl Chloride 36, 24 (in Chinese). 